BIBLIOTIKA : Jurnal Kajian Perpustakaan dan Informasi

Volume 2 Nomor 1, 2018

Journal homepage : $\underline{\text { http://journal2.um.ac.id/index.php/bibliotika }}$

\title{
KAJIAN SEMIOTIK TERHADAP SATUAN RUANG PERPUSTAKAAN
}

\author{
Purwani Istiana*, Faruk H.T., Sizie Handayani \\ Mahasiswa Prodi Kajian Budaya dan Media, Universitas Gadjah Mada, Yogyakarta, Indonesia
}

\begin{tabular}{|c|c|}
\hline A R T I C L E I N F O & A B S T R A C T \\
\hline $\begin{array}{l}\text { Keyword: } \\
\text { Ruang Perpustakaan, } \\
\text { Satuan Ruang, } \\
\text { Semiotika }\end{array}$ & $\begin{array}{l}\text { Penelitian ini bertujuan mendeskripsikan satuan ruang -satuan ruang yang ada di } \\
\text { Perpustakaan Kota Yogyakarta Metode yang digunakan adalah metode semiotika. Hasil } \\
\text { penelitian menunjukkan bahwa ada satuan ruang yang tidak sesuai dengan kaidah dan ada } \\
\text { satuan ruang baru yang ditampilkan oleh Pengelola. }\end{array}$ \\
\hline
\end{tabular}

\section{PENDAHULUAN}

Perpustakaan sebagai perangkat penunjang sebuah lembaga pendidikan untuk mencapai tujuan pembelajaran. Sebagai sarana untuk mendukung aktivitas pendidikan, penelitian, pelestarian informasi dan rekreasi, perpustakaan masih memberi kesan yang kurang menarik bagi masyarakat. Kesan masyarakat umum tentang perpustakaan adalah tempat yang pengap, berdebu, tidak nyaman dan berisi buku-buku yang kuno atau ketinggalan zaman (Rahmadhani, 2011). Di sisi lain saat ini keberadaan internet telah memberikan kemudahan bagi masyarakat untuk mengakses informasi, baik untuk kebutuhan pendidikan, penelitian maupun untuk rekreasi. Keberadaan sumber informasi online memudahkan masyarakat untuk mengakses berbagai informasi. Sumber informasi online seolah semakin menjauhkan masyarakat dari institusi yang bernama perpustakaan.

Ruang perpustakaan seolah dapat digantikan dengan tempat makan, tempat nongkrong seperti café-café yang banyak bermunculan dengan menyediakan akses internet bagi pengunjung yang datang. Sementara tingkat kunjungan masih menjadi tolok ukur keberhasilan sebuah perpustakaan. Hal ini menuntut perpustakaan untuk melakukan perubahan agar mampu tetap eksis di tengah masyarakat. Perpustakaan melakukan perubahan atas komponen perpustakaan yaitu gedung atau ruang, perabotan, koleksi, aktivitas layanan dan pengelolanya (staf yang melayani). Posisi gedung perpustakaan di tengah keramaian masyarakat, pemilihan perabot yang nyaman dan menarik, penambahan koleksi dengan yang lebih baru dan dengan format digital, variasi aktivitas layanan terutama yang memudahkan akses informasi serta pengelola yang lebih professional dalam melakukan pelayanan merupakan beberapa contoh perubahan yang dilakukan perpustakaan.

Penampilan fisik perpustakaan menjadi salah satu daya tarik bagi masyarakat untuk datang ke perpustakaan. Perpustakaan tradisional yang hanya membatasi pada peminjaman dan pengembalian buku, sudah mulai ditinggalkan oleh pengelola perpustakaan. Penampilan perpustakaan mengalami beberapa perubahan. Perubahan-perubahan tersebut dapat dilihat salah satunya melalui keberadaan satuan ruang perpustakaan dan komposisinya. Satuan ruang perpustakaan- satuan ruang perpustakaan merupakan tanda yang bermakna bagi sebuah perpustakaan. Disebutkan oleh Barthes (2012) bahwa tanda merupakan penggabungan penanda dan petanda. Penanda merupakan ranah ekspresi, sedangkan petanda merupakan ranah isi. Satuan ruang perpustakaan merupakan tanda yang memiliki ranah ekspresi dan ranah isi. Komposisi satuan tanda ruang perpustakaan didasarkan pada prinsip umum penempatan ruang dan tata ruang pada Buku Pedoman Perpustakaan tahun 2009. Sebagaimana umumnya sebuah perpustakaan, setiap

\footnotetext{
* Corresponding author.

E-mail addresses: dian_eka09@yahoo.com (Dian Eka Chandra Wardhana)
}

ISSN : 2579-3802 (Online) - BIBLIOTIKA : Jurnal Kajian Perpustakaan dan Informasi is licensed under Creative Commons AttributionShareAlike 4.0 International License (http://creativecommons.org/licenses/BY/4.0/).

50 | BIBLIOTIKA : Jurnal Kajian Perpustakaan dan Informasi 
perpustakaan memiliki beberapa satuan ruang perpustakaan sesuai dengan buku pedoman standar perpustakaan.Satuan ruang-satuan ruang tersebut disusun oleh pengelola perpustakaan. Keberadaan satuan ruang perpustakaan serta susunan satuan ruang merupakan sebuah produksi makna yang dilakukan pengelola perpustakaan. Satuan ruang -satuan ruang tersebut merupakan tanda-tanda yang disusun oleh pengelola bukan tanpa maksud dan makna yang ingin disampaikan kepada penggunanya.

Penelusuran penulis terhadap penelitian yang dilakukan penulis terkait satuan ruang perpustakaan dengan metode semiotika belum dilakukan sebelumnya. Penelitian yang dilakukan oleh Closet-Crane (2009) dengan mengkaji delapan teks Library Information Science (LIS) yang membahas tentang perencanaan dan desain perpustakaan. Penelitian ini menggunakan analisis wacana kritis Norman Fairclough sebagai metodologi. Penelitian ini dilatarbelakangi oleh adanya pertanyaan besar pada akhir abad ke-20 atas peran perpustakaan secara fisik setelah hadirnya revolusi digital dan adanya konstruksi dan renovasi perpustakaan perguruan tinggi yang telah meningkat. Berdasarkan analisis teks, ditemukan tema besar dalam teks LIS terkait dengan perencanaan dan desain perpustakaan yaitu perpustakaan sebagai Information Commons (IC), perpustakaan sebagai Learning Commons (LC), dan perpustakaan dirancang untuk belajar (Libraries Designed for learning). Closet-Crane (2009) juga mengkaji lebih jauh pengaruh tema-tema tersebut terhadap praktek profesional serta perencanaan dan desain perpustakaan. Penelitian lain dilakukan oleh oleh Bouthillier (1996) meneliti juga tentang makna layanan perpustakaan umum di Quebec. Bagaimana pengelola perpustakaan memaknai layanan perpustakaan, tidak cukup memberikan gambaran yang jelas tentang fenomena layanan perpustakaan umum. Phillips (2012) tentang persepsi masyarakat terhadap perpustakaan umum selama kampanye pendanaan perpustakaan. Penelitian ini menunjukkan peran bahasa dan wacana dalam pembentukan persepsi masyarakat terhadap perpustakaan umum. Hasil penelitian melalui wacana tentang persepsi perpustakaan memberikan dukungan bagi perpustakaan sebagai alat yang kuat untuk advokasi pendanaan perpustakaan. Penelitian

Berdasarkan beberapa tinjauan pustaka di atas penulis belum menemukan penelitian yang mengkaji satuan ruang perpustakaan yang disediakan oleh sebuah perpustakaan sebagai sebuah tanda, yang memiliki makna yang ingin disampaikan pengelola kepada pengguna perpustakaan. Closet-Crane (2009) mengkaji desain perpustakaan dengan objek teks Library Information Science (LIS), sedangkan Bouthillier (1996) lebih kepada makna layanan perpustakaan, dan Phillips (2012) lebih focus pada peran bahasa dan wacana dalam membentuk persepsi masyarakat terhadap perpustakaan. Kebaruan dalam penelitian ini adalah melihat perpustakaan dari sudut pandang satuan ruang perpustakaan sebagai sebuah tanda yang ditampilkan perpustakaan dalam sebuah komposisi yang memiliki makna.

Tujuan penelitian ini adalah untuk mengidentifikasi satuan ruang- satuan ruang apa saja yang disediakan oleh pengelola perpustakaan yang berpedoman pada Pedoman Tata Ruang dan Perabot Perpustakaan Umum tahun 2009 dan Standar Nasional Perpustakaan Umum Kabupaten /Kota 2011. serta bagaimana komposisi satuan ruang disusun oleh pengelola perpustakaan.

\section{METODE PENELITIAN}

Metode penelitian ini menggunakan metode semiotika. Metode semiotika merupakan metode yang mengidentifikasi satuan-satuan tanda, menentukan relasi antar satuan tanda dan menetapkan makna. Satuan ruang perpustakaan sebagai sebuah tanda atau satuan tanda. Pengumpulan data menggunakan observasi dan dokumentasi. Peneliti melakukan observasi terhadap satuan ruang-satuan ruang yang ada di Perpustakaan Kota Yogyakarta, serta komposisi ruangnya. Analisis didasarkan pada Buku Pedoman Perpustakaan Tahun 2009 dan standar perpustakaan tahun 2011 (sebagai Kaidah yang digunakan). Wawancara mendalam dilakukan terhadap informan yaitu pengelola perpustakaan yang dipandang memiliki informasi yang cukup lengkap tentang satuan ruang-satuan ruang perpustakaan.

\section{HASIL PENELITIAN}

Berdasarkan hasil observasi terhadap satuan ruang -satuan ruang yang ada di Perpustakaan Kota Yogyakarta, pada bulan .... maka diketahui bahwa Perpustakaan Kota Yogyakarta memiliki 23 satuan ruang. Rincian satuan ruang dan komposisi satuan ruang ada di Tabel 1. Sementara dalam Kaidah terdapat 22 satuan ruang perpustakaan.

Tabel 1. Satuan Ruang-Satuan Ruang di Perpustakaan Kota Yogyakarta

\begin{tabular}{|l|l|l|}
\hline No & \multicolumn{1}{|c|}{ Satuan Ruang } & \multicolumn{1}{c|}{ Komposisi Satuan Ruang } \\
\hline 1 & $\begin{array}{l}\text { Ruang Bahan Pustaka Umum } \\
\text { dan Ruang Baca }\end{array}$ & Di Lantai 1, di sebelah barat ruang pelayanan \\
\hline 2 & $\begin{array}{l}\text { Ruang Bahan Pustaka Anak dan } \\
\text { Ruang Baca }\end{array}$ & di lantai 2, di sebelah barat ruang diskusi, \\
\hline
\end{tabular}

51 | BIBLIOTIKA : Jurnal Kajian Perpustakaan dan Informasi 


\begin{tabular}{|c|c|c|}
\hline 3 & $\begin{array}{l}\text { Ruang Bahan Pustaka Referensi } \\
\text { dan Ruang Baca }\end{array}$ & $\begin{array}{l}\text { Ruang ini digabung, berada di lantai } 2 \text {, sehingga } \\
\text { ruang ini saling melengkapi. }\end{array}$ \\
\hline 4 & $\begin{array}{l}\text { Ruang Koleksi Majalah \& Surat } \\
\text { Kabar dan Ruang Baca }\end{array}$ & \\
\hline 5 & $\begin{array}{l}\text { Ruang Koleksi Bahan Pustaka } \\
\text { Pandang Dengar dan Ruang } \\
\text { Baca }\end{array}$ & Berada di lantai 2, persis di depan tangga lantai 2. \\
\hline 6 & $\begin{array}{ll}\text { Ruang Kerja } & \text { Kepala } \\
\text { Perpustakaan } & \\
\end{array}$ & Di lantai 1 , di sebelah ruang kerja tata usaha \\
\hline 7 & Ruang Kerja Tata Usaha & Di lantai 1 \\
\hline 8 & $\begin{array}{l}\text { Ruang Kerja Pengelolaan Bahan } \\
\text { Pustaka }\end{array}$ & Di lantai 1, ada di belakang, di Selatan Mushola \\
\hline 9 & $\begin{array}{lll}\text { Ruang } & \text { Kerja } & \text { Pengembangan } \\
\text { Koleksi }\end{array}$ & Di lantai 1 , di sebelah utara ruang pelayanan \\
\hline 10 & Ruang Pelayanan & Berada di lantai 1, di depan pintu masuk lantai 1 \\
\hline 11 & Ruang Pelayanan katalog & Berada di lantai 1 di sebelah selatan pintu masuk \\
\hline 12 & Ruang Penitipan Tas & $\begin{array}{l}\text { Berada di bawah tangga lantai } 1 \text { dan berada di luar, } \\
\text { disisi selatan dan utara }\end{array}$ \\
\hline 13 & Ruang Lobi dan ruang pamer & Berada di lantai 1, di depan ruang layanan \\
\hline 14 & Ruang Pertemuan & Berada di lantai 2 , disebelah ruang baca referensi. \\
\hline 15 & Ruang Diskusi & $\begin{array}{l}\text { Di lantai } 2 \text { di sisi sebelah selatan, dan di sebelah } \\
\text { timur ruang koleksi dan baca anak. }\end{array}$ \\
\hline 16 & Gudang & Ada di lantai 1 di bagian belakang. \\
\hline 17 & WC & $\begin{array}{l}\text { Berada di halaman depan, di dalam lantai } 1 \text {, di } \\
\text { lantai } 2 \text { ada } 2 \text {, serta ada juga yang ada di lantai } 1 \\
\text { dibagian belakang ada dua. }\end{array}$ \\
\hline 18 & Mushola & Ada di sisi belakang barat halaman perpustakaan \\
\hline 19 & Tempat Parkir & Berada di halaman depan gedung perpustakaan. \\
\hline 20 & Garasi Mobil & $\begin{array}{l}\text { Ada di halaman bagian samping selatan gedung } \\
\text { perpustakaan,kapasitas }\end{array}$ \\
\hline 21 & Ruang Keamanan/Pos Satpam & $\begin{array}{l}\text { Di halaman perpustakaan di sisi sebelah Selatan } \\
\text { dan di sisi sebelah barat Gazebo }\end{array}$ \\
\hline 22 & $\begin{array}{lll}\text { Ruang } & \text { Layanan } & \text { Pendaftaran } \\
\text { WiFi } & & \end{array}$ & $\begin{array}{l}\text { Ruang layanan WiFi terletak di depan ruang } \\
\text { pelayanan. }\end{array}$ \\
\hline 23 & Ruang Gazebo \&Shelter & $\begin{array}{l}\text { Di halaman depan perpustakaan di sisi sebelah } \\
\text { selatan dan timur }\end{array}$ \\
\hline
\end{tabular}

\section{PEMBAHASAN}

Berdasarkan hasil penelitian di atas, akan kita bandingkan dalam Kaidah (Buku Pedoman Perpustakaan tahun 2009 dan pada Standar Nasional Perpustakaan Umum kabupaten/kota tahun 2011). Dua buku tersebut merupakan kaidah yang menjadi dasar dalam analisis satuan ruang-satuan ruang yang ada di perpustakaan. Satuan ruang yang ada dalam buku Pedoman dan Standar ada 22 satuan ruang. Dari 22 satuan ruang tersebut ada satuan ruang yang tidak dimiliki oleh perpustakaan yaitu satuan ruang bahan pustaka remaja dan ruang bacanya. Keterbatasan ruang menjadi alasan utama mengapa perpustakaan tidak menyediakan ruang bahan pustaka remaja. Pengelola perpustakaan menyampaikan bahwa pemustaka remaja dapat membaca koleksi remaja yang digabung di dalam koleksi bahan pustaka umum. Namun di dalam ruang bahan pustaka tidak disediakan khusus bahan pustaka khusus remaja.

Satuan ruang yang tidak disebut dalam buku Pedoman maupun Standar adalah ruang layanan pendaftaran WiFi dan ruang Gazebo \& ruang Shelter. Ruang layanan pendaftaran WiFi digunakan untuk pengunjung memperoleh password WiFi. Bagi pengelola ruang layanan ini digunakan untuk mengontrol akses WiFi.

Komposisi satuan ruang perpustakaan umum, yang dirangkum dari buku Pedoman Perpustakaan Umum 2009, menjelaskan bahwa susunan satuan ruang perpustakaan perlu memperhatikan prinsip umum penempatan ruang dan tata ruang, sebagai berikut: 1 . Memungkinkan pengunjung masuk ke jajaran koleksi perpustakaan dan memanfaatkannya, sehingga tidak diperlukan adanya sekat pemisah antara area koleksi dan area baca. 2. Kejelasan antara area untuk membaca serius, membaca santai dan ruang untuk diskusi.3. Ada pemisahan area untuk kelompok usia yang berbeda, namun masih memungkinkan terjadinya kontak 52 | BIBLIOTIKA : Jurnal Kajian Perpustakaan dan Informasi 
antar area. 4. Ruang insidentil (ruang pertemuan, lobi dan ruang pameran) penempatannya tidak mengganggu layanan perpustakaan sehari-hari.

Semua bentuk tampilan perpustakaan baik tampilan fisik maupun dalam keseharian layanan pustakawannya merupakan bentuk-bentuk pesan yang ingin disampaikan pengelola perpustakaan kepada pengguna perpustakaan bahkan seluruh masyarakat luas Kota Yogyakarta. Tampilan perpustakaan dalam hal ini ruang yang disediakan, komposisi antar ruang, selalu mengalami perubahan.

Prinsip pertama dalam penempatan ruang adalah open access (Lestari, 2017), memungkinkan pengunjung masuk ke jajaran koleksi perpustakaan dan memanfaatkannya, sehingga tidak diperlukan adanya sekat pemisah antara area koleksi dan area baca. Di Perpustakaan Kota Yogyakarta, pengunjung dapat secara bebas masuk dalam jajaran koleksi dan tidak ada sekat pemisah antara area koleksi dan area baca. Hal ini memungkinkan pengguna langsung dapat membaca koleksi berdekatan dengan lokasi koleksi itu berada. Gambar 1 menunjukkan tidak ada sekat antara area koleksi dan area baca. Kondisi ini dapat diinterpretasikan bahwa perpustakaan memberikan kebebasan bagi penggunaanya untuk menikmati bahan pustaka baik di dalam ruang koleksi maupun ruang baca. Relasi sintagmatik antara satuan ruang bahan pustaka dan ruang bacanya adalah sejajar.

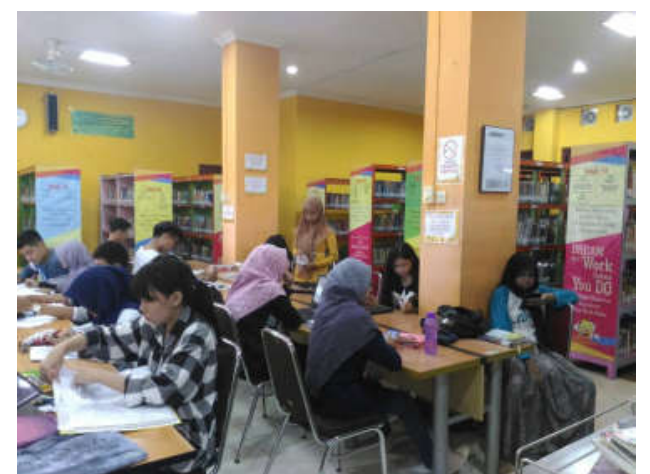

Gambar 1. Tidak ada sekat antara area koleksi dan area baca.

Prinsip kedua dalam penataan atau penempatan ruang perpustakaan adalah perlu kejelasan antara area untuk membaca serius, membaca santai dan ruang untuk diskusi. Untuk ruang membaca serius, pengelola menyatakan belum memiliki ruang semacam ini. Perpustakaan belum memiliki ruang yang dapat dimanfaatkan untuk membaca secara pribadi dan bersifat serius. Untuk membaca santai dan membaca serius, perpustakaan menyediakan secara gabung di ruang baca masing-masing ruang bahan pustaka, di ruang Gazebo \& ruang Shelter. Namun sebenarnya ruang membaca santai dan ruang membaca serius memiliki relasi yang kontras, sehingga tidak dapat digabungkan. Sebagaimana penelitian Closet-Crane (2009), yang menyebutkan tema besar dalam Library Information Science bahwa salah satunya adalah perpustakaan dirancang untuk belajar. Dengan demikian ketersediaan area membaca serius atau pribadi merupakan hal penting dalam sebuah perpustakaan.

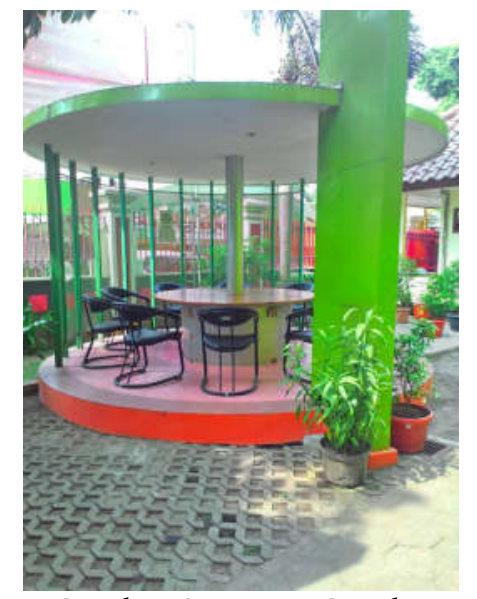

Gambar 2. Ruang Gazebo 


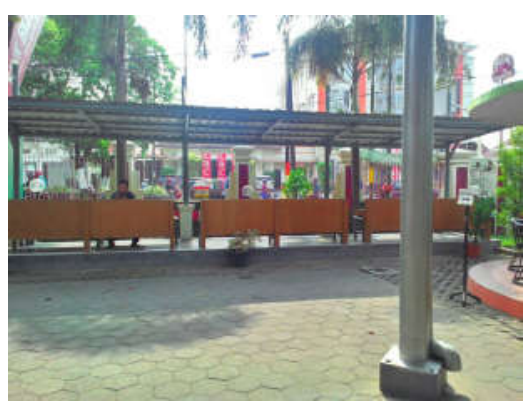

Gambar 3. Ruang Shelter

Ruang yang memiliki kejelasan fungsi adalah ruang diskusi. Ruang diskusi ini disediakan khusus di lantai 2, disebelah timur ruang bahan pustaka anak dan ruang bacanya. Menurut Pengelola Perpustakaan, ruang diskusi ini merupakan hasil dari studi banding yang dilakukan pengelola di Perpustakaan Daerah Riau (Perpustakaan Tingkat Propinsi). Berdasarkan pengetahuan yang diperoleh setelah studi banding tersebut, Pengelola menerapkan ketersediaan ruang diskusi bagi masyarakat di Perpustakaan Kota Yogyakarta. Ruang diskusi menurut Pengelola dimaksudkan sebagai tempat bagi pengguna untuk melakukan diskusi kelompok. Ruang diskusi cukup diminati oleh masyarakat. Mengapa ruang diskusi yang kemudian diakomodir oleh pengelola perpustakaan? Hal ini perlu diskusi lebih lanjut tentang makna terkait keberadaan ruang diskusi.

Prinsip ketiga adanya ruang pemisah antara kelompok usia yang berbeda, ditampilkan oleh Pengelola dengan menyediakan ruang bahan pustaka anak dan ruang bacanya, dan ruang bahan pustaka umum dan ruang bacanya. Ruang bahan pustaka anak berada di lantai 2, sebelah timur ruang bahan pustaka referensi dan ruang bacanya. Ruang bahan pustaka umum dan ruang bacanya berada di lantai 1 , berada di sebelah barat ruang pelayanan, dan berada di sebelah timur ruang kerja tata usaha.

Pengelola mengatakan bahwa keberadaan ruang bahan pustaka umum dan ruang bacanya dimaksudkan agar pengunjung yang datang ke perpustakaan, masuk ke gedung perpustakaan dapat langsung menemukan bahan pustaka umum yang ada di lantai satu dan di ruangan di dekat koleksi di simpan tersebut pengunjung dapat langsung membacanya. Ruang bahan pustaka umum ini diperuntukkan bagi pengguna remaja dan dewasa (umum). Hal ini disampaikan pengelola, mengingat keterbatasan ruang dan remaja masih memungkinkan untuk digabung dengan pembaca umum. Relasi antar satuan ruang bahan pustaka umum dan ruang bahan pustaka remaja adalah identik.

Keberadaan pemisahan ruang baca anak dan ruang ruang baca untuk umum dimaksudkan agar pengunjung dewasa merasa tenang dan nyaman, dan pengunjung anak-anak juga demikian. . Ruang bahan pustaka anak dan ruang bacanya dimaksudkan juga untuk menyediakan bahan pustaka anak yang mudah didapat masyarakat di Perpustakaan Kota Yogyakarta dengan ruang baca khusus anak.

Pengelola mengatakan bahwa keberadaan ruang bahan pustaka umum dan ruang bacanya dimaksudkan agar pengunjung yang datang ke perpustakaan, masuk ke gedung perpustakaan dapat langsung menemukan bahan pustaka umum yang ada di lantai satu dan di ruangan di dekat koleksi di simpan tersebut pengunjung dapat langsung membacanya.

Prinsip ke empat ruang insidentil (ruang pertemuan, lobi dan ruang pameran) penempatannya tidak mengganggu layanan perpustakaan sehari-hari. Ruang pertemuan berada di lantai 2 perpustakaan. Ruang ini bersebelahan dengan ruang baca majalah dan ruang baca referensi. Ruang pertemuan bersekat tidak permanen, sehingga jika ruang pertemuan tidak digunakan maka digunakan sebagai ruang baca. Demikian juga sebaliknya ketika ruang pertemuan memerlukan kapasitas ruang yang lebih luas, maka akan menggunakan ruang baca majalah dan referensi. Dengan demikian ruang pertemuan tersebut dapat dinilai mengganggu layanan perpustakaan. Ruang lobi dan ruang pameran, berada di lantai 1 perpustakaan. Ruang ini hanya sedikit menggunakan ruang di depan pintu masuk perpustakaan dan tidak mengganggu layanan perpustakaan sehari-hari.

Penempatan satuan ruang-satuan ruang perpustakaan merupakan sebuah sintagmatik spasial dapat dijelaskan bahwa satuan ruang pos keamanan berada di samping kanan gedung perpustakaan atau di sebelah selatan gedung. Satuan ruang parkir berada di depan gedung perpustakaan dan di sebelah selatan satuan ruang Gazebo. Secara detail sintagmatik spasial dapat dilihat pada Tabel 1. Sintagmatik temporal satuan ruang-satuan ruang tersebut dapat dijelaskan bahwa pengunjung dari satuan ruang parkir, akan menuju ke ruang pelayanan WiFi dan layanan kunci Loker. Selanjutnya akan menuju satuan ruang penitipan tas. Dari satuan ruang penitipan tas, pengunjung akan menuju ke satuan ruang lain sesuai kebutuhannya (Satuan Ruang Gazebo; Satuan ruang bahan pustaka; satuan ruang pertemuan; satuan ruang diskusi dan satuan ruang lainnya). 


\section{PENUTUP}

Simpulan

Simpulan dalam penelitian ini adalah ada kesenjangan antara satuan ruang yang riil ada di perpustakaan dan yang ada di dalam Kaidah. Satuan ruang yang tidak ada di Perpustakaan Kota Yogyakarta adalah satuan ruang bahan pustaka remaja dan ruang bacanya. Sedangkan satuan ruang yang tidak ada dalam Kaidah namun ada di Perpustakaan yaitu satuan ruang layanan WiFi, dan satuan ruang Gazebo \& Shelter.

Komposisi satuan ruang perpustakaan ada yang belum memenuhi kaidah dalam penempatan satuan ruang. Tidak ada kejelasan ruang untuk membaca serius dan membaca santai. Ruang membaca serius dan membaca santai digabung dalam ruang baca masing-masing bahan pustaka dan ruang Gazebo, dimana kedua fungsi ruang tersebut dalam prinsip penempatan ruang memiliki relasi yang kontras. Satuan ruang yang memiliki kejelasan fungsi adalah satuan ruang diskusi.

Ada penggabungan ruang bahan pustaka umum dan ruang bacanya dengan ruang bahan pustaka untuk remaja. Penggabungan satuan ruang bahan pustaka referensi dan bahan pustaka majalah.

Ruang pertemuan berada di samping ruang baca bahan pustaka referensi dan ruang bahan pustaka majalah dan surat kabar. Ruang ini memiliki relasi sejajar. Dalam pemanfaatan ruang ini saling mengisi. Sekat ruang pertemuan yang tidak permanen. Pemanfaatannya dapat diperluas dengan menggunakan ruang baca bahan pustaka referensi. Artinya dalam pemanfaatan ruang pertemuan ini terkadang mengganggu layanan sehari-hari perpustakaan. Hal ini tidak sesuai dengan Kaidah penempatan ruang.

Dalam penelitian ini masih terbatas pada pembahasan deskriptif tentang satuan ruang-satuan ruang perpustakaan serta makna yang masih parsial. Muncul beberapa pertanyaan sebagai contoh mengapa pengelola tidak memprioritaskan ruang bahan pustaka remaja, namun kemudian muncul satuan ruang Gazebo yang tidak ada dalam kaidah. Permasalahan lain yang belum terjawab, yakni tentang makna encoding dan decoding dari setiap penempatan dan prioritas satuan ruang yang disediakan oleh pengelola perpustakaan. Permasalahan tersebut akan terjawab dalam disertasi selanjutnya.

\section{DAFTAR PUSTAKA}

Atmodiwirjo, Paramita \& Yatmo, Yandi Andri. 2009. Pedoman Tata Ruang dan Perabot Perpustakaan Umum. Jakarta: Perpustakaan Nasional RI.

Barthes, Roland. 2012. Elemen-elemen Semiologi. Yogyakarta: Jalasutra

Bouthillier, France. 1996. The meaning of service: An ethnographic study of a public library in quebec (Order No. NN11678). Available from ProQuest Dissertations \& Theses Global. (304318015). Retrieved from http://search. proquest.com /docview/ 304318015 ?accountid =13771

Buku Pedoman Perpustakaan tahun 2009

Closet-Crane, Catherine. (2009). (Re)Creating the Academic Library as Place for the 21st Century? A Critical Analysis of Discourse in Discussions of Academic Library Planning and Design. United States: ProQuest LLC.

Lestari, A. D. (2017). Menentukan Skala Prioritas Sistem Informasi Layanan Opac Studi Kasus Di Badan Perpustakaan Umum Dan Arsip Daerah Kabupaten Tulungagung. Bibliotika: Jurnal Kajian Perpustakaan Dan Informasi, 1(1), 81-90. https://doi.org/10.17977/um008v1i12017p081

Perpustakaan Nasional RI. (2011). Standar Nasional Perpustakaan. Jakarta: Perpustakaan Nasional RI.

Phillips, Amy. (2012). Framing the public library: The public perception of the public library in the media (Order No. 3534052). Available from ProQuest Dissertations \& Theses Global. (1240572830). Retrieved from http://search.proquest.com/docview/1240572830?accountid=13771

Atmodiwirjo, Paramita \& Yatmo, Yandi Andri. (2009). Pedoman Tata Ruang dan Perabot Perpustakaan Umum. Jakarta: Perpustakaan Nasional RI.

Rahmadhani, Suhersi. (2011). Membangun Citra Perpustakaan Ideal, dalam

http://arpusda.jatengprov.go.id/index.php?option=com_content\&view=article\&id=811:membangun -citra-perpustakaanideal\&catid=47:perpustakaan-asrip-perpustakaan\&Itemid=119. 